\title{
Characterization and prevention of formation damage for fractured carbonate reservoir formations with low permeability
}

\author{
Shu Yong ${ }^{1,2}$ and Yan Jienian ${ }^{1,2} *$ \\ ${ }^{1}$ Key Laboratory of Petroleum Engineering, Ministry of Education, China University of Petroleum, Beijing 102249, China \\ ${ }^{2}$ School of Petroleum Engineering, China University of Petroleum, Beijing 102249, China
}

\begin{abstract}
Stress sensitivity and water blocking in fractured carbonate reservoir formations with low permeability were determined as the main potential damage mechanisms during drilling and completion operations in the ancient buried hill Ordovician reservoirs in the Tarim Basin. Geological structure, lithology, porosity, permeability and mineral components all affect the potential for formation damage. The experimental results showed that the permeability loss was $83.8 \%-98.6 \%$ caused by stress sensitivity, and was $27.9 \%-48.1 \%$ caused by water blocking. Based on the experimental results, several main conclusions concerning stress sensitivity can be drawn as follows: the lower the core permeability and the smaller the core fracture width, the higher the stress sensitivity. Also, stress sensitivity results in lag effect for both permeability recovery and fracture closure. Aimed at the mechanisms of formation damage, a modified low-damage mixed metal hydroxide (MMH) drilling fluid system was developed, which was mainly composed of low-fluorescence shale control agent, filtration control agent, lowfluorescence lubricant and surfactant. The results of experimental evaluation and field test showed that the newly-developed drilling fluid and engineering techniques provided could dramatically increase the return permeability (over $85 \%$ ) of core samples. This drilling fluid had such advantages as good rheological and lubricating properties, high temperature stability, and low filtration rate (API filtration less than $5 \mathrm{ml}$ after aging at $120 \quad{ }^{\circ} \mathrm{C}$ for 4 hours). Therefore, fractured carbonate formations with low permeability could be protected effectively when drilling with the newly-developed drilling fluid. Meanwhile, field test showed that both penetration rate and bore stability were improved and the soaking time of the drilling fluid with formation was sharply shortened, indicating that the modified MMH drilling fluid could meet the requirements of drilling engineering and geology.
\end{abstract}

Key words: Fractured carbonate formations with low permeability, stress sensitivity, water blocking, MMH drilling fluids, formation damage control

\section{Introduction}

Micro-fractured carbonate reservoirs with low permeability are commonly characterized by high clay content, high water saturation, complicated pore structures, high sensitivity to fresh water, high capillary pressure, severe water blocking, severe anisotropy and high flow resistance, and have abundant natural micro-fractures. During drilling and production operations, stress sensitivity damage can be easily induced by a change in effective stress. Water sensitivity and water-blocking can also be easily caused by various invading fluids (Bennion et al, 2000; Erwom et al, 2003; Lin, et al, 2003; Ren et al, 2004). Furthermore, the damage to permeability of formations is largely irreversible. Experimental results show that permeability loss caused by stress sensitivity can never be ignored. It commonly ranges

*Corresponding author. email: yanjienian@sina.com Received April 7, 2008 from $25 \%$ to $60 \%$ (Zhang et al, 2006), and the loss caused by water-blocking ranges from $70 \%$ to $90 \%$ (Bennion et al, 1999). Much higher permeability loss can result from stress sensitivity and can be observed from experimental results for targeted low-permeability fractured formations. This paper introduces the damage characteristics of tight carbonate reservoir formations with low permeability in the Tarim Basin, and presents an approach to preventing formation damage from stress sensitivity and water blocking during drilling and completion operations.

\section{Geological characteristics of target formations}

The Ordovician reservoirs in the Tarim Basin are the type of carbonate fracture-porosity dual-permeability reservoirs, and are mainly controlled by geological conditions, development of fractures and dissolution cavities. The target formation mainly consists of grayish-brown silt-sized 
crystalline limestone and micrite, with a few calcarenites, and dolostones. The permeability of the target formation is $(0.01-36.38) \times 10^{-3} \mu \mathrm{m}^{2}$. The effective porosity ranges from $0.11 \%$ to $6.76 \%$. The permeability and porosity of the target formation are extremely low, and secondary corrosion holes, cavities and fractures form the main storage space rather than the carboncete matrix. The average width of formation fractures is generally less than $10 \mu \mathrm{m}$. Clay minerals are mainly augenetic, distributed in holes and cavities and the total content is commonly less than 5\%. Among clay minerals, illite accounts for $33 \%-70 \%$, with an average value of $58.5 \%$; illite/smectite (I/S) accounts for $14 \%-33 \%$, with an average value of $25.6 \%$; kaolinite accounts for $0-27 \%$, with an average value of $11.3 \%$; and chlorite accounts for $0-34 \%$, with an average value of $10.1 \%$.

\section{Main mechanisms of formation damage}

Sensitivity tests for core samples taken from the target formation show that the formations are characterized by weak sensitivity to flow rate, weak to medium sensitivity to water and weak sensitivity to salt, and strong sensitivity to acid. More attention has been paid to sensitivity to stress and water-blocking, which is discussed in detail below.

\subsection{Experimental evaluation of sensitivity to stress}

Sensitivity to stress can be defined as the impact of effective stress (the differential between overburden pressure and pore pressure) on the permeability of the target formation, which is mainly caused by compression and closure of capillaries and pores. Unlike mid- and highpermeability formations, fluid flow in low-permeability formations is affected by the slippage effect, therefore various forms of flow exist. The strong sensitivity to stress is mainly caused by non-linear gas flow in porous media. The lower the formation permeability, especially in fracture-porosity channels, the more remarkable the effect on stress sensitivity (Luo et al, 2005). Sensitivity to stress is usually related to formation permeability, water saturation, confining pressure and displacement pressure.

\subsubsection{Preparation of core samples and test procedure}

Natural outcrop core samples taken from the Ordovician fractured formation were drilled to the desired size and served as core groundmass of man-made fractured cores. The cores were then split into two parts along the axial direction by applying pressure, and fine particles on the fracture surface was blown off with $\mathrm{N}_{2}$. Finally, the two sections were cemented by resin.

The experiments were performed by using JHMF-II flowing apparatus designed for cores to simulate in situ stress state of formations. The experimental procedure adopted was as follows: 1) Firstly, the core size was measured, the dry core sample was weighted and $\mathrm{N}_{2}$ permeability was measured. 2) The green core was weighed after evacuation saturated with simulated formation brine, and then the porosity of cores could be calculated. 3) The permeability to brine could be obtained after the core was set in the test-apparatus and displaced with brine until the displacing pressure was kept constant. 4) The core was then displaced with kerosene until irreducible water saturation, $S_{\mathrm{wi}}$, was established. The value of $S_{\mathrm{wi}}$ is generally related to rock property, formation temperature and pressure. Afterwards, the correlation between the permeability to oil and displacement pressure could be determined. For all the tests, the displacement rate was $1 \mathrm{ml} /$ min and the confining pressure was controlled at 1-25 $\mathrm{MPa}$.

\subsubsection{Impact of stress on core permeability and fracture width}

Based on above-mentioned test procedure, correlation between effective stress and permeability or fracture width of cores taken from five wells in the target formation was measured and shown in Fig. 1.

It can be seen from Fig. 1 that both permeability and fracture width initially declined quickly with increasing effective stress. When the effective stress increased to over $10 \mathrm{MPa}$, the decline rate tended to slow down. When the effective stress was over $14 \mathrm{MPa}$, the permeability loss ranged from $83.8 \%$ to $98.6 \%$, with an average value of $93.38 \%$; the fracture width decreased by $71.1 \%-88.5 \%$, with an average value of $76.5 \%$.

The low-permeability cores taken from the fractured formation usually have relatively stronger sensitivity to stress, which results in the alteration of the original relations of loadbearing frame particles, fractures and pore-throat structures. The fractures and pore throats tend to close down with increasing effective stress. Consequently, the reduction in the width of fluid flow channels will lead to a decrease in the permeability of the cores. However, when stress increases to a specific value, because relatively low values of permeability and fracture width are reached, core permeability and fracture width change only slightly with further increasing stress, therefore stress sensitivity tends to weaken.

3.1.3 Impact of effective stress on core porosity

Double cycles of stress loading/unloading experiments were performed. The first cycle of stress loading/unloading experiment referred to the values of porosity that were measured at the confining pressure of 3, 5, 7, 10, 20 and $30 \mathrm{MPa}$, respectively. Then stress was gradually unloaded afterwards a second cycle of stress experiment was performed in the same way. The correlation of core porosity and effective stress was measured, and it was shown that cores porosity reduced slightly with increasing effective stress. The reduction in the core porosity was less than $5 \%$ during the first stress loading experiment, and the reduction was less than $2 \%$ during the second stress loading experiment. It is considered that core porosity mainly depends on what the core volume is. Particles in the core deformed slightly after being compacted during the rock-forming process. The reason why the alteration of core porosity in the first cycle of loading/unloading experiment is higher than that in the second cycle is as below: There mainly exist double actions, which are compaction and compression, chiefly compaction during the first cycle of stress loading/unloading experiment, therefore alteration of core porosity is relatively high. However, alteration of core porosity becomes less in the second cycle of loading/unloading experiment due to the end of compaction and chiefly compression. All in all, it can be considered that alteration of effective stress can do little harm to core porosity. 


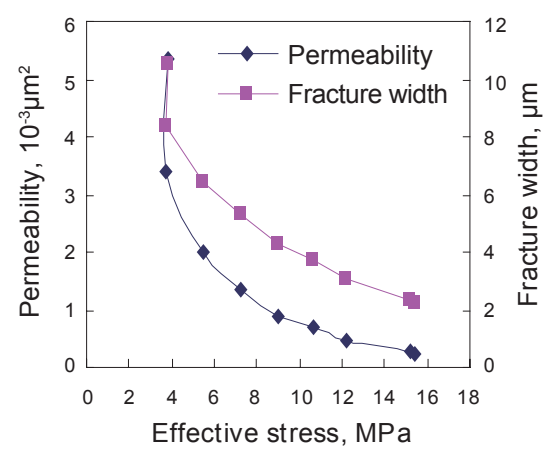

(a) Core No. A35

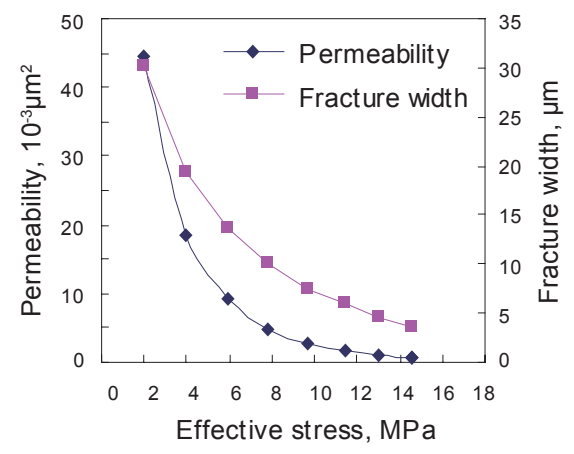

(b) Core No. B17

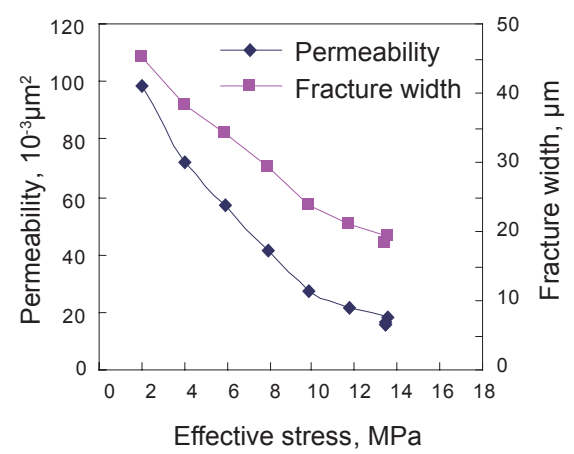

(c) Core No. B36

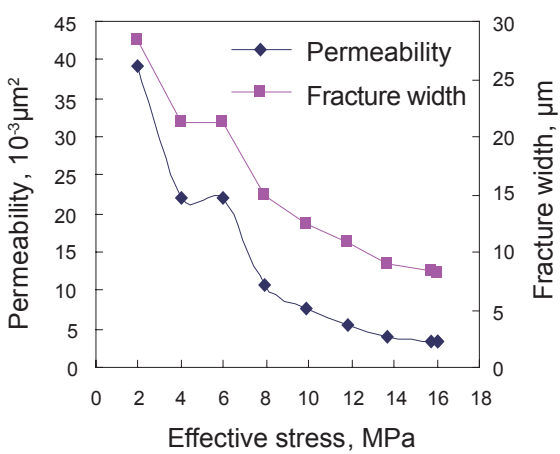

(d) Core No. C21

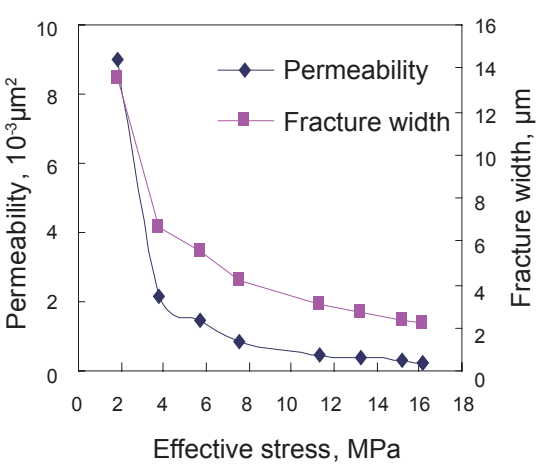

(e) Core No. C37

Fig. 1 Impact of effective stress on core permeability and fracture width

\subsubsection{Lag effect of sensitivity to effective stress}

During practical oil field production, every alteration of production parameters, such as intermittent well operating, adjustment of production pressure differential, etc. can inevitably result in alteration of formation pore structure, furthermore, formation permeability and fracture width are seriously damaged. The impact of stress sensitivity on core permeability during stress loading/unloading was evaluated, as shown in Fig. 2.

The following phenomenon can be seen from Fig. 2: 1) During effective stress loading, the higher the stress was applied, the more seriously the core permeability was damaged, and hence the higher the stress sensitivity was. However, there exists a stress sensitivity point. When effective stress is higher than such a value, effective stress has relatively less damage to core permeability, hence, stress sensitivity becomes obviously weaker. 2) The stress sensitivity point in the process of stress unloading is lower than that in the process of stress loading, namely, there exists an obvious lag effect of stress sensitivity, and with the increase of cycles of stress loading/unloading, the lag effect becomes weaker, but once being damaged, permeability can not recover to its original value. This can be caused by the deformation of the fracture surface of the dual-permeability formation, which results from the continuous effective stress. This is the so-called lag effect of fracture closure.

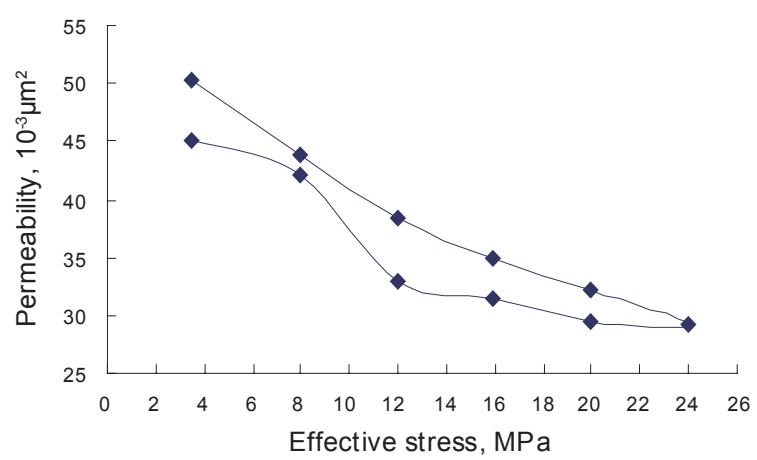

(a) Core No. B18

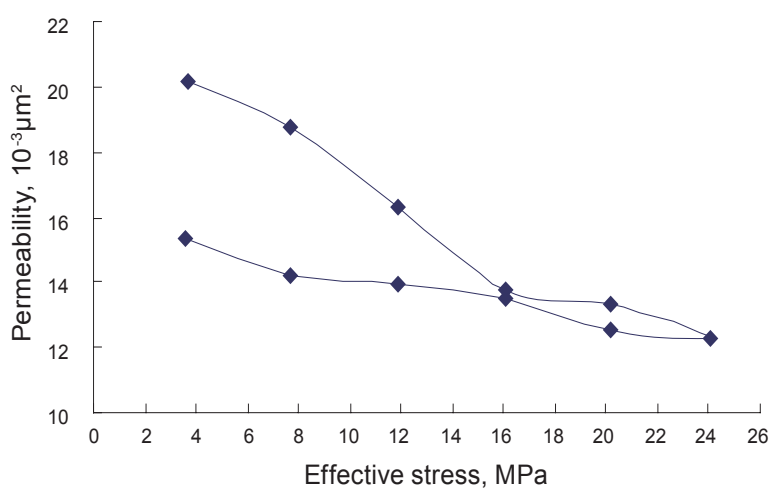

(b) Core No. C36

Fig. 2 Impact of stress sensitivity on core permeability during several cycles of loading and unloading 


\subsection{Evaluation of water-blocking damage}

As pore throats in the low-permeability formations are extremely small, water blocking is commonly considered one of the main damaging factors. Hence, evaluation of water-blocking damage was also undertaken. The testing procedure was as follows: Core samples were from taken the target formation, confining pressure during entire experiment remained above stress sensitivity point to reduce the stress sensitivity effect. Firstly, $\mathrm{N}_{2}$ permeability was measured by using dry core, and the cores were vacuum saturated by standard brine, then the core was displaced with kerosene to leaving irreducible water remaining in the core, and then core permeability $K_{\text {op }}$ was measured by displacing with kerosene in the forward direction after it was contaminated by brine in the reverse direction. Finally the rate of permeability damage $R_{\mathrm{s}}$ was calculated. All displacing tests were performed by using the JHMD-II intelligent core flooding apparatus.

Table 1 shows that the damage rate $R_{\mathrm{s}}$ induced by water blocking is relatively higher, ranging from $27.9 \%$ to $48.1 \%$. The lower the original water saturation $S_{\mathrm{wi}}$ and $\mathrm{N}_{2}$ permeability $K_{\mathrm{a}}$, the higher the damage rate $R_{\mathrm{s}}$, indicating more severe water blocking effect. As can be known from the capillary pressure equation and Bennion's equation (Bennion et al, 1995) of predicting water blocking effect that water blocking damage is mainly related to such parameters as $K_{\mathrm{a}}$, $S_{\text {wi, }} \varphi$ and $\theta$ (oil/water interfacial tension) and other factors such as lithology, type and content of cementing substance, pore structure and properties of invasion fluids, etc. Hence, it can never be ignored. Theoretically, 1) In order to minimize capillary force, various types of treating agents and measures can be used to reduce surface tension and alter original formation water wettability to nearly intermediate wettability, namely $\theta$ is approximately $90^{\circ}$ (basing on equation 1). 2) Meanwhile, to improve permeability in the near wellbore zone by adopting some operations such as acidizing and fracturing, etc, water-blocking damage can also be effectively minimized or eliminated.

$$
p_{\mathrm{c}}=\frac{2 \sigma \cos \theta}{r}
$$

where $p_{\mathrm{c}}$ is capillary force, $\theta$ is contact angle, $r$ is radius of pore throat or contracted capillary.

Table 1 Evaluation results of water-blocking damage for cores from fractured carbonate formation

\begin{tabular}{|c|c|c|c|c|c|c|}
\hline \multirow{2}{*}{$\begin{array}{l}\text { Core } \\
\text { number }\end{array}$} & \multirow{2}{*}{$\begin{array}{c}\text { Porosity } \\
\varphi, \%\end{array}$} & \multirow{2}{*}{$\begin{array}{l}\text { Original water saturation } \\
\qquad \mathrm{S}_{\mathrm{wi}}, \%\end{array}$} & \multirow{2}{*}{$\begin{array}{c}\mathrm{N}_{2} \text { permeability } \\
K_{\mathrm{a}}, 10^{-3} \mu \mathrm{m}^{2}\end{array}$} & \multicolumn{2}{|c|}{ Core permeability, $10^{-3} \mu \mathrm{m}^{2}$} & \multirow{2}{*}{$\begin{array}{c}\text { Core damage rate } \\
R_{s}\end{array}$} \\
\hline & & & & Before fluid blocking & After fluid blocking & \\
\hline 1 & 3.2 & 14.2 & 18.0 & 10.6 & 5.5 & 48.1 \\
\hline 2 & 4.5 & 15.2 & 7.3 & 3.4 & 1.8 & 47.0 \\
\hline 3 & 4.7 & 23.6 & 25.3 & 14.7 & 10.6 & 27.9 \\
\hline
\end{tabular}

\section{Protective techniques during drilling and production operations}

\subsection{Mechanism of sensitivity to stress}

Some characteristics concerning sensitivity to stress can be summarized as below from above mentioned experimental results. 1) Tested cores have obvious sensitivity to stress, the permeability of cores are drastically reduced with the increase in effective stress. 2) There exists a stress sensitivity point, above which stress sensitivity becomes weaker. 3) During the decrease in stress, there exists an obvious lag effect of stress sensitivity or fracture closure, and the more times the stress was applied, the weaker the lag effect of stress sensitivity or fracture closure. 4) Cores with low permeability or small fracture width can not fully recover their permeability values after stress was applied. All tested cores failed to recover their original permeabilities. The following reasons can probably explain the stress sensitivity of low-permeability fractured formation. 1) There are abundant micro-fractures in the rock. Micro-fractures can easily be closed after stress is applied. Furthermore, these closed fractures can not be fully recovered after the stress is unloaded. This is the socalled lag effect of stress, or lag effect of fracture closure. 2) The pore structure of the target formation complicates the stress action. Pore space is extremely small, but the change in pore space resulting from stress change is relatively greater. Hence, when the stress applied is lower than stress sensitivity point, stress sensitivity is generally very high. 3 ) Pore throats and pore channels in the core are compressed by stress. Especially, when effective stress is lower than stress sensitivity point, fluid flow capacity declines because pore throats and pore channels are compressed by stress. Namely, the measured core permeability declines. However, when pore throats and pore channels are compressed to a specific extent, namely reaching the stress sensitivity point, the extent or tendency of being compressed becomes relatively smaller, and correspondingly the decline of core permeability becomes smaller. 4) Various formations have different extents of stress sensitivity, which mainly depends on compaction effect, type and content of rock mineral composition, packing substances in fractures and their types and contents (Ostensen, 1986; Ruan and Wang, 2002). 


\subsection{Prevention of damage induced by sensitivity to stress during drilling and production operations}

For a given formation, the value of effective stress mainly depends on pore pressure. The higher the pore pressure, the smaller the effective stress. Therefore, some necessary preventive measures should be taken into account. For example, a reasonable range of negative pressure for underbalanced drilling and tripping operation should be kept so as to maintain a higher pore pressure, and effectively prevent formation damage caused by overly negative pressure, partial excessive lower pore flow pressure or overly big surge pressure resulting from tripping operation. The sensitivity to stress can lead to even more serious damage in the process of production. Hence, it is necessary to keep a reasonable production pressure differential and possibly avoide unnecessary well shut-in to effectively prevent damage caused by sensitivity to stress.

\section{Formulations and properties of low- damage drilling fluids used in fractured carbonate formations}

Low-damage drilling fluids are generally composed of fracture-packing agents (such as asbestos fiber and sized calcium carbonate), soft particles of oil-soluble resin and some strongly inhibitive agents. In addition, a special filmforming agent can be used to plug up the fractures with various widths very quickly and effectively. This drilling fluid system is characterized by a high stress bearing capacity, low drainage pressure and high permeability recovery, etc $(\mathrm{Li}$, 2001; Lu et al, 2004; Zhang and Yan, 2004; Zhao et al, 2007).

\subsection{Requirements of low-damage drilling fluids}

Under-balanced or near-balanced drilling technology has been widely applied to penetrating targeted formations in the Tarim Basin. According to the main damage mechanisms for the Ordovician fractured carbonate formations, the basic technical approaches to designing a low-damage drilling fluid are as follows: 1) All kinds of treating agents used in drilling fluids should be compatible with formation rock and brine so as to minimize formation damage during drilling operations; 2) Efficient filtration control agents should be optimized to form quickly high-quality mud cake so as to reduce invasion depth of drilling fluids under a given positive pressure differential; 3) Efficient surfactants should be optimized so as to reduce oil/water interfacial tension, and minimize formation damage induced by water-blocking; 4) Maintaining a reasonable density of drilling fluids and controlling an appropriate range of surge pressure, so as to prevent formation damage induced by sensitivity to stress.

\subsection{Characteristics of low-damage MMH drilling fluid}

The MMH electropositive colloid drilling fluid has formation protective functions such as reducing clay particle invasion, inhibiting hydration and swelling, high drainage rate and high permeability recovery, etc.
In the MMH drilling fluid system, bentonite can react with the MMH particles and water to form a special spatial network structure (Zhang et al, 2000). The size of this network structure formed is usually bigger than that of pore throat and micro-fracture width. Consequently, clay particles invasive depth is restricted. The flexible plugging at pore throats formed by compound network structure can be deformed and later effectively drained out of formation. Unlike solid particle plugging, which needs high drainage pressure and in which possibly the blocks at the pore throats can hardly be drained out, organic MMH particles can be easily dissolved by oil and acid, which can further improve oil/gas phase permeability by means of the flowback of oil and acidizing treatments, etc. At the same time, $\mathrm{MMH}$ drilling fluid can effectively inhibit clay hydration, swelling, and has strong resistance to salt sensitivity, so it has unique performance for fractured carbonate reservoir protection.

\subsection{Formulations and properties of drilling fluids}

Considering that all kinds of treating agents should meet the requirements of formation lithology, physical properties, sensitivity characteristics and well logging, it is necessary to select shale-controlling agents with low-fluorescence, filtration control agents, lubricants and surfactants properly, so as to improve the performance of the MMH drilling fluids. On the basis of experiments, a typical formulation of the MMH drilling fluid is listed as below: 4\% bentonite $+7 \%$ MMH + 2\% SMP-1 + 2\% WFT-666 + 3\% CHSP-1 + 3\% DFD- $140+0.2 \%$ SP-2 $+2 \%$ MHR86D (lubricant) $+0.2 \%$ $\mathrm{ABSN}+4 \% \mathrm{CaCO}_{3}$.

For some formations, an alternative drilling fluid system can also be used to enhance the plugging effectiveness further. Its formulation is as below: $4 \%$ bentonite $+7 \% \mathrm{MMH}$ $+2 \%$ SMP- $1+2 \%$ WFT- $666+3 \%$ CHSP- $1+3 \%$ DFD- 140 $+0.2 \% \mathrm{SP}-2+2 \% \mathrm{MHR}-86 \mathrm{D}+0.2 \% \mathrm{ABSN}+2 \% \mathrm{QCX}-1+$ $1.5 \%$ DYY-1 (an oil-soluble resin) $+4 \% \mathrm{CaCO}_{3}$.

5.3.1 Evaluation of rheological properties

Experimental results in Table 2 show that all the rheological parameters are rational. Meanwhile, the API filtration rate is less than $5 \mathrm{ml}$.

5.3.2 Compatibility between drilling fluids and formation rocks

The test sample was prepared by mixing $350 \mathrm{ml}$ of lowdamage drilling fluid with 40 grams of dry drilled cuttings. The drilled cuttings were dried at $100{ }^{\circ} \mathrm{C}$ for 4 hours and then screened to 10 mesh. According to the differential weights of cores before and after aging, compatibility between the drilling fluid and formation rock can be evaluated. The experimental results are shown in Table 3 . It can be found that the drilling cuttings recovery was over $99 \%$, and no obvious change happened in color and shape after aging, illustrating an excellent compatibility.

\subsubsection{Compatibility between drilling fluids and formation brine}

The low-damage drilling fluids were mixed with formation brine in a proportion of 1:2 using an $8000 \mathrm{r} / \mathrm{min}$ high-speed mixer. After aging for 1 hour, no deposition and cloudiness were observed, illustrating that drilling fluids are compatible with formation brine. 
5.3.4 Measurements of returned permeability for cores contaminated with drilling fluids

The JHMD-II core flooding test apparatus was used to measure the return permeability. The test procedures are as follows: 1) The man-made fractured core, by mixing cores taken from Ordovician fractured carbonate formations with filling substances (in a proportion of smectite:illite: $\mathrm{CaCO}_{3}$ : formation brine $=1: 10: 30: 90$ ) was $2.54 \mathrm{~cm}$ in-diameter and $2.75 \mathrm{~cm}$ in length. The man-made core was saturated with simulated formation brine after being vacuum dried; 2) The permeability, $K_{\mathrm{S}}$, was measured by displacment with kerosene at a confining pressure of $4 \mathrm{MPa}$ and a displacement rate of $1.0 \mathrm{ml} / \mathrm{min} ; 3$ ) Under the same conditions, the permeability, $K_{\mathrm{S}}$ ', was measured after being contaminated with low-damage drilling fluids in the opposite direction, the return permeability, which is herein defined as the percent permeability that is recovered, was calculated.

The test results are listed in Table 4. It can be seen that the return permeability of two core samples contaminated with the $\mathrm{MMH}$ drilling fluid are all over $87 \%$, indicating good protective effect.

Table 2 Rheological properties of low-damage drilling fluids

\begin{tabular}{cccccccc}
\hline Experimental conditions & $\begin{array}{c}\text { Density } \\
\rho, \mathrm{g} / \mathrm{cm}^{3}\end{array}$ & $\begin{array}{c}\text { Apparent viscosity } \\
A V, \mathrm{mPa} \cdot \mathrm{s}\end{array}$ & $\begin{array}{c}\text { Plastic viscosity } \\
P V, \mathrm{mPa} \cdot \mathrm{s}\end{array}$ & $\begin{array}{c}\text { Yield point } \\
Y P, \mathrm{~Pa}\end{array}$ & $\begin{array}{c}\text { Gel strength } \\
10^{\prime \prime} / 10^{\prime}, \mathrm{Pa}\end{array}$ & $\begin{array}{c}\text { API filtration loss } \\
\mathrm{ml}\end{array}$ & $\mathrm{pH}$ value \\
\hline Before aging & 1.14 & 48.5 & 43.0 & 5.5 & $2 / 15$ & 4 & 8.5 \\
After aging & 1.14 & 30.0 & 25.0 & 5.0 & $1 / 5$ & 5 & 9.0 \\
\hline
\end{tabular}

Notes: 1) Aging at $120^{\circ} \mathrm{C}$ for 16 hours

Table 3 Compatibility between low-damage drilling fluid and formation cores

\begin{tabular}{cccc}
\hline \multirow{2}{*}{$\begin{array}{c}\text { Core } \\
\text { number }\end{array}$} & \multicolumn{2}{c}{ Weight of core, $\mathrm{g}$} & $\begin{array}{c}\text { Recovery percent } \\
\%\end{array}$ \\
\cline { 2 - 4 } 1 & Before being contaminated & After being contaminated & 99.5 \\
2 & 39.76 & 39.56 & 99.3 \\
\hline Average & 40.15 & 39.86 & 99.4 \\
\hline
\end{tabular}

Table 4 Return permeability of cores contaminated with low-damage drilling fluids

\begin{tabular}{|c|c|c|c|}
\hline $\begin{array}{c}\text { Core } \\
\text { number }\end{array}$ & $\begin{array}{l}\text { Initial permeability } \\
\qquad K_{\mathrm{s}}, 10^{-3} \mu \mathrm{m}^{2}\end{array}$ & $\begin{array}{c}\text { Permeability after being exposed to } \\
\text { drilling fluid } K_{\mathrm{s}}^{\prime}, 10^{-3} \mu \mathrm{m}^{2}\end{array}$ & $\begin{array}{c}\text { Return permeability } \\
\%\end{array}$ \\
\hline 1 & 5.36 & 4.68 & 87.3 \\
\hline 2 & 7.12 & 6.29 & 88.3 \\
\hline Average & & & 87.8 \\
\hline
\end{tabular}

\subsection{Field application}

The modified low-damage MMH drilling fluid was used for drilling the target formation in Well LG-6. This was a high-slope directional wildcat well located in the Tarim Basin. The hole inclination angle was $62.4^{\circ}-69.7^{\circ}$. The penetration depth was 5,471-5,890 $\mathrm{m}$. The coefficient of formation pressure was 1.12 and formation temperature was $120^{\circ} \mathrm{C}$.

The rheological parameters of the field mud were measured and shown in Table 5. The return permeability of cores contaminated with the mud were over $85 \%$ (Table 6), indicating only a slight extent of damage measured.

The results of field tests show that this low-damage $\mathrm{MMH}$ drilling fluid had good rheological and lubricating properties, as well as low filtration rates during drilling the target formation. The friction resistance during tripping operation was only 2-3 tons. The borehole was regular and no collapse happened. The main measures adopted during drilling 
operations included controlling concentration of ABSN not less than $0.2 \%$; reinforcing solids control, cleaning out useless solid particles as much as possible, keeping the proportion between drilling cuttings and bentonite less than $3: 1$, controlling reasonable density of drilling fluid to minimize stress sensitivity caused by great positive differential pressure and reducing drilling duration as much as possible, etc.

Table 5 Rheological properties of field mud $\left(120^{\circ} \mathrm{C} / 16 \mathrm{~h}\right)$

\begin{tabular}{|c|c|c|c|c|c|c|c|c|c|c|c|c|}
\hline $\begin{array}{l}\text { Mud } \\
\text { types }\end{array}$ & $\underset{\mathrm{g} / \mathrm{cm}^{3}}{\rho}$ & $\begin{array}{l}\mu \\
\mathrm{s}\end{array}$ & $\begin{array}{c}A V \\
\mathrm{mPa} \cdot \mathrm{s}\end{array}$ & $\begin{array}{c}P V \\
\mathrm{mPa} \cdot \mathrm{s}\end{array}$ & $\begin{array}{l}Y P \\
\mathrm{~Pa}\end{array}$ & $\begin{array}{l}G 10^{n} / 10^{\prime} \\
\mathrm{Pa}\end{array}$ & $\begin{array}{l}\text { API filtrdtion loss } \\
\mathrm{ml} / \mathrm{mm}\end{array}$ & $\begin{array}{l}\text { HTHP filtrdtion loss } \\
\mathrm{ml} / \mathrm{mm}\end{array}$ & $\begin{array}{c}\text { Sticking } \\
\text { coefficient } \\
K_{f} \\
\end{array}$ & $\begin{array}{c}\text { Flow } \\
\text { behavior } \\
\text { index } n\end{array}$ & $\begin{array}{l}\text { Consistency } \\
\text { index } \\
K, \mathrm{~Pa} \cdot \mathrm{s}^{n}\end{array}$ & $\mathrm{pH}$ value \\
\hline 1 & 1.15 & 51 & 31.5 & 24.0 & 7.5 & $3.5 / 8$ & $4.5 / 0.5$ & $9.8 / 1.0$ & 0.02 & 0.69 & 0.27 & 8.5 \\
\hline 2 & 1.15 & 50 & 32.0 & 24.5 & 7.5 & $3.0 / 8$ & $4.5 / 0.5$ & $9.5 / 1.0$ & 0.02 & 0.68 & 0.26 & 9.0 \\
\hline
\end{tabular}

Table 6 Return permeabilities of core samples from Well LG-1

\begin{tabular}{cccc}
\hline $\begin{array}{c}\text { Core } \\
\text { number }\end{array}$ & $\begin{array}{c}\text { Initial permeability } \\
K_{\mathrm{s}}, 10^{-3} \mu \mathrm{m}^{2}\end{array}$ & $\begin{array}{c}\text { Permeability after being exposed to drilling fluid } \\
K_{\mathrm{s}}^{\prime}, 10^{-3} \mu \mathrm{m}^{2}\end{array}$ & $\begin{array}{c}\text { Return permeability } \\
\%\end{array}$ \\
\hline 3 & 9.38 & 8.14 & 86.8 \\
4 & 8.41 & 7.20 & 85.6 \\
\hline Average & & 86.2 \\
\hline
\end{tabular}

Notes: The core samples were taken at a depth of $5585 \mathrm{~m}$

\section{Conclusions}

1) The main storage space in fractured carbonate formation with low-permeability includes micro-pores and micro-fractures. The sensitivities to effective stress and water blocking are determined as the two major damage factors.

2) Experimental results showed that the permeability loss caused by increasing effective stress ranged from $83.8 \%$ to $98.6 \%$, indicating quite a strong sensitivity to stress, while the permeability loss caused by water blocking ranged from $27.9 \%$ to $48.1 \%$.

3) The sensitivity to stress is mainly related to the characteristics of fractures and the structure of pores in formations, as well as the value of the effective stress applied. The main factors affecting water blocking include rock permeability, initial water saturation and oil/water interfacial tension, as well as other factors such as lithology of formation and properties of invading fluids.

4) The modified low-damage MMH drilling/completion fluid not only had excellent compatibility with rock and brine of the target formations, but also had good rheological properties, low filtration rate and high return permeability. Field applications showed smaller friction coefficient during tripping operation, regular boreholes and absence of collapse.

5) The low-damage MMH drilling fluid is multifunctional, minimizing invasion depth of solid particles, effectively inhibiting clay hydration and swelling, reducing salt-sensitivity, high drainage rate and high permeability due to its network structure formed by clay particles, water molecules and MMH colloid particles. Therefore, the modified low-damage MMH drilling fluid could be used for protecting fractured carbonate reservoirs during drilling.

\section{Acknowledgements}

The authors gratefully acknowledge Project of the National Natural Science Foundation of China (No. 50574061) for the partial support of this work.

\section{References}

Bennion D B, Thomas F B, Bietz R F, et al. Water and hydrocarbon phase trapping in porous media. CIM paper. 1995

Bennion D B, Thomas F B, Bietz R F, et al. Remediation of water and hydrocarbon phase trapping problems in low permeability gas reservoirs. JCPT. 1999. 38(8): 39-48

Bennion D B, Thomas F B and Ma T. Formation damage processes reducing productivity of low permeability gas reservoirs. 2000. SPE paper 60325

Erwom M D, Riersom C R and Bennion D B. Brine imbibition damage in the Colville River Field, Alaska. 2003. SPE paper 84320

Li D F. Damage evaluation of drilling/completion fluids system to carbonate rock fractured reservoir. Drilling \& Production Technology. 2001. 24(5): 85-87 (in Chinese)

Lin G R, Shao C G, Xu Z F, et al. Fluid damage and solution method study of low permeability gas reservoir. Petroleum Exploration and Development. 2003. 30(6): 117-118 (in Chinese)

$\mathrm{Lu} \mathrm{H}, \mathrm{Wu}$ X H and Qu L M. Studies on using polyols in water base 
drilling fluids for fissured carbonatestone reservoirs. Oilfield Chemistry. 2004. 21(3): 205-207 (in Chinese)

Luo R L, Cheng L S, Peng J C et al. The relationship between stresssensitivity permeability and starting pressure gradient of reservoir. Journal of Southwest Petroleum Institute. 2005. 27(3): 20-22 (in Chinese)

Ostensen R W. The effect of stress dependent permeability on gas production and well testing. SPE Formation Evaluation. 1986. 1(3): 227-235 (SPE paper 11220)

Ren X J, Zhang N S, Zhang X F, et al. Damage of residual water on permeability of tight gas reservoir. Natural Gas Industry. 2004. 24(11): 106-108 (in Chinese)

Ruan M and Wang L G. Low permeability oilfield development and pressure-sensitive effect. Acta Petrolei Sinica. 2002. (5): 73-76 (in Chinese)
Zhang C G, Xu T T and Hou W G. Mixed metal layered hydroxide compound drilling fluid. Beijing: Petroleum Industry Press. 2000. 52-56 (in Chinese)

Zhang J B and Yan J N. New theory and method for optimizing the particle size distribution of bridging agents in drilling fluids. Acta Petrolei Sinica. 2004. 25(4): 88-91 (in Chinese)

Zhang Q, Du J F, Cui L C, et al. Study on stress sensitivity of the reservoir rock in Sulige gas oilfeld. Drilling Fluid and Completion Fluid. 2006. 23(5): 29-30(in Chinese)

Zhao J Z, Xue Y Z and Li G R. Formation damage control for lowpermeability reservoir during drilling operation in Shengli Oilfield. Journal of China University of Petroleum (Edition of Natural Science). 2007. 31(3): 148-151 (in Chinese)

(Edited by Sun Yanhua) 